\title{
A Physical Activity Practice Index for Older Students and Adults
}

\author{
By Paul Godbout ${ }^{*} \&$ Luc Nadeau
}

\begin{abstract}
This article puts forward a physical activity practice (PAP) index that could be used by older students (high school and college level) and adults who wish to monitor their PAP in order to regulate it. Authors explain the origin of the PAP index, identify PAP aspects such as frequency, duration, intensity and diversity as they relate to the index and describe the simple mechanics of its computation. Then, they discuss physical literacy (PL) awareness in terms of competence, knowledge and understanding, motivation toward PAP, and actual physical activity (PA) engagement. Regulation scenarios are presented in association with individuals' PAP awareness. Finally, a few suggestions are added with regard to tailored PAP monitoring for more engaged physical literate persons. The PAP index described is intended to help individuals monitor their PAP over time, taking simultaneously into account its intensity and volume whatever the selected activity(ies). Willingness to monitor one's PAP implies at least a minimal level of PL awareness. Besides reflecting on their PA-related knowledge and PA competency and capacities, individuals ought to understand their reasons for engaging into the regular practice of $P A$. Based on their answers to such questions, they can then engage into regulation scenarios with the help of monitoring instruments such as the one discussed in this article.
\end{abstract}

Keywords: physical literacy, physical-literacy awareness, physical-activitypractice awareness, FITT formula, PAP monitoring

\section{Introduction}

There has been over the last decade a considerable interest in the operationalization of the physical literacy (PL) construct following Whitehead's first proposals on the subject (Whitehead 1993, 2001). The PL-journey scaffold she put forward (Whitehead 2013b) involves several categories of practitioners associated with physical activity in such contexts as physical education (PE), sport education, dance education, outdoor education, recreation education and health education. Concerning the relationship between PL and PE, Whitehead (2013a, p. 32) wrote: "...physical literacy is not an alternative to physical education, nor is it in competition with physical education. Physical education is a subject area in the school curriculum while physical literacy is the goal of physical education". As individuals enter adulthood, fitness leaders and health-education practitioners take over in the promotion of regular physical activity in various areas, conditions and phases of adults' lives.

Over the years, assessment instruments have been developed to provide practitioners with physical-activity-practice (PAP) formative and/or summative

*Professor Emeritus, Laval University, Canada.

${ }^{ \pm}$Professor, Laval University, Canada. 
assessment tools. For reviews, readers may consult, for instance, Biddle et al. (2011), Hickerson (2011), Hills et al. (2014), McLain and Tudor-Locke (2009) and Sylvia et al. (2014). Measurement techniques vary from the use of recording devices (accelerometers, pedometers, heart rate monitors, armbands) to the use of direct observation, self-report questionnaires or self-report activity diaries/logs.

Self-report diaries, requiring participants to record PA in real time, provide more data, especially when time intervals between recordings are shorter [15minute intervals over three days in the case of the Bouchard's Physical Activity Record (BAR) (Bouchard et al. 1983)]. Their main disadvantage is the time and discipline required from participants who have to record their activity several times a day. Moreover, questionnaires do not require so much recording time and depend more on the recall capacity of responders. They may vary as to the variables considered (e.g., mode, duration, or frequency of PA), measures reported (e.g., activity scores, time, calories), types of data (e.g., measures of intensity, differentiating between habitual and merely recent activities, inclusion of leisure and non-leisure activity), and modalities of data recording (e.g., paper and pencil assessment, computerized questionnaire, interview) (Sylvia et al. 2014). Selfreport questionnaire reliability depends on the recall capacity of responders and may therefore become questionable when lag-time exceeds several weeks (Sallis and Saelens 2000). It has been reported however that reliability is relatively high with young-to-middle aged adults, "especially when intervals between tests were one month or less" (Sallis and Saelens 2000, p. 2). These authors also report high reliability for students when data were recorded the same day. The same conclusion likely applies for adults.

The increasing attention on PL in relation with PE has resulted in the development of several assessment instruments for PL (Barnett et al. 2020, Cairney et al. 2018, Longmuir et al. 2018, Payne et al. 2013, Robinson and Randall 2017). While some are physical-competence oriented, others are more concerned with physical activity profiles. Questions have been raised as to their alignment with the four constituents of the construct (physical competence, knowledge and understanding, lifetime engagement, motivation and competence) (Robinson and Randall 2017). These authors wrote (2017, p. 44):

She [Whitehead] has further recognized the challenges associated with "assessing" physical literacy, suggesting, "charting progress is more appropriate than assessment" (p. 48). In writing about physical literacy and physical education, Whitehead (2013b) has explained that physical literacy is an individualized "personal journey," proposing that any assessment should be in relation to one's own previous assessment. She leaves no ambiguity in this regard: "there is no reference to benchmarks or comparison with others" (Whitehead 2013c, p. 45).

Far from being a passive experience, the development of an individual's PL is a learner-centered, situated, and socio-constructivist process. The goal of PE is therefore to endow the becoming adult with self-direction, self-actualization and self-regulation capacities. PAP assessment procedures briefly reviewed above tend to be used in research studies and may be seen as cumbersome in the context of an individual's every-day PA. In many cases, such measurement instruments are not 
user-friendly and not necessarily conducive to a reflection on one's PA habits. There appears to be a need for a procedure that could be used in an educational set-up (PE classes) at the high school and/or college level while offering a strong carry-over value for after-school life. The purpose of this article is to put forward a physical activity practice (PAP) index that could be easily used by older students and adults who need or wish to monitor their PAP in order to regulate it. After presenting the background of the index, the PAP aspects involved and its computation, the authors discuss the regulation of one's PL level, considering PL awareness, motivation toward PAP, and regulation scenarios.

\section{The Physical Activity Practice Index}

In this article, the authors have elected not to consider the assessment of PL per se but the regular self-assessment of one of its components, physical activity practice (PAP) as a reflection of one's lifetime engagement. Moreover, the authors' objective is to come up with a self-monitoring instrument that would help students at the high-school and college levels and adults regulate their weekly, monthly and yearly practice of physical activity, taking into account all kinds of contingencies. In their search for a suitable instrument, the authors were inspired by the Team-Pentathlon, a program developed by a group of PE teacher-educators from Laval University in Quebec City, Canada (Martel et al. 2011).

\section{Origin of the Physical Activity Practice Index: The Team Pentathlon}

In schools, several practitioners and specialists have proposed different methods involving students in assessing their PAP (Westerterp 2009). These methods have always had as a common characteristic the measurement of the volume of practice (quantitative measures) such as the duration and the frequency of exercise bouts. However, given the great diversity of activities selected and also the fact that all these activities did not have the same energy requirement, some studies have also attempted to bear in mind the type of physical activity (qualitative measure) in the calculation. Martel et al. (2011) proposed a calculation formula that considers the quantity and type of physical activity practice in the Team Pentathlon program. In this eight-week program, each student is required to indicate the frequency, duration, and type of physical activity they perform daily. Each activity is weighted according to the average level of energy expenditure (METs) while performing the activity. By multiplying the weight (or correction factor) by the duration, the authors defined a unit called Pentathlon Hour (PH). The main physical activities practiced by students are therefore classified into one of four weight-categories $(1.0 ; 0.75 ; 0.5 ; 0.25)$. More intense activities like running for example have a weight of 1 , meaning that 60 minutes of running is equal to $1 \mathrm{PH}$, while less intense activities as walking, for instance, has a weight of 0.25 , meaning that the same duration of 60 minutes of walking is equal to $0.25 \mathrm{PH}$. In addition, activities to be selected by students are classified according to five type-categories: (1) aquatics; (2) team sports and games; (3) endurance (aerobic) 
activities; (4) individual sports and games or artistic activities; (5) dual sports and games. Over a period of eight weeks, students have to achieve individual PAP standards formulated in terms of PHs. A report on the number of PHs performed by the students is available every other week so that they can regulate their practice. The particular standard to be achieved over the 8-week period (between 20-30 PHs) is chosen by the students before the start of the program.

Peer influence and social network is an important part of adopting regular physical activity for students (Girard et al. 2021). In the Team Pentathlon format, students are regrouped in teams composed of 5 or 6 students so they can count on each other to schedule PA bouts. In addition to each student setting his or her personal PAP goal, team members also determine the standard they want to collectively achieve. Depending upon the number of PHs achieved AND the number of activity-categories in which the minimum number of PHs is reached, one of five standards can be claimed (excellence, gold, silver, bronze or honor). Thus, the program is designed to encourage not only PAP in general but also a diversity of preferences in terms of types of activity. The authors of Team Pentathlon also developed an adaptation of their program for adults (Gagnon et al. 2021). The simplicity of the measurement of PAP in this program could serve as a model for establishing a simple PAP index for each individual who would therefore assess his or her individual practice. Such an assessment would be criterion-related rather than normative. In other words, and in line with Whitehead's recommendations referred to earlier (Robinson and Randall 2017), any assessment by individuals would be personal and in relation with their own objectives.

\section{Aspects of Physical Activity Practice to be Considered}

Based on their knowledge of acute and chronic effects of physical activity on the human body, exercise physiologists have, for a long time, pinpointed various PA characteristics that can be considered. For instance, several decades ago, Bouchard et al. (1974) published a textbook intended for senior-high-school and college level students registered in physical fitness and well-being PE classes. They identified five distinct dimensions of regular PA practice: nature, form, intensity, duration and frequency. While the nature of the activity refers to the kind of activity performed, like sport, dance and muscular exercises, its form refers to the continuous or discontinuous way one individual exercises. For instance, one may run or swim without interruption for a long period of time or elect to exercise more strenuously, alternating bouts of exercise with rest periods, a form referred to as interval training. Intensity may refer to a percentage of maximal capacity of an individual in terms of METs or $\mathrm{O}^{2}$ uptake, or to a percentage of maximal muscle strength in the case of muscular exercises. Frequency usually refers to the number of times per week, while duration refers to the time length of one PA session.

Over the years, the combination of such aspects of PA practice have come to be known as the FITT formula (Corbin et al. 2014, Corbin et al. 2018). As mentioned above, $\mathbf{F}$ and $\mathbf{I}$ stand for frequency and intensity; the first $\mathbf{T}$ stands for time (duration) and the second $\mathbf{T}$ stands for type, meaning the kind of activity 
selected in view of a specific outcome (for instance, cardiovascular endurance, muscular endurance or flexibility). With regard to the type of activity, it is thus possible to categorize most activities normally practiced by adults in order to help them determine their own standards of practice (FITT-formula specifics) to maintain a healthy lifestyle (Daley and Duda 2006). Variations as to the type of activity selected will be qualified as diversity. In developing a calculation procedure for monitoring PA practice, the authors established, as a premise, that it should ideally take four elements into account as they are associated with healthy and effective physical activity: frequency, duration (or time), intensity and diversity. Combinations of frequency, duration and intensity will make up a volume of PA whereas diversity will reflect variations as to the type of activity selected.

\section{Frequency and Duration}

Considering all physical activities performed by an individual that can be related to improving one's health should be that individual's first preoccupation if he/she wishes to improve or maintain a healthy lifestyle (Barisic et al. 2011, Delisle et al. 2010, Rodgers and Sullivan 2001). It is the first and easiest method to assess one's progress and confirm the regularity of one's practice over a certain period of time (one week, one month or one season). As is the case for Team Pentathlon, it seems important and more practical to determine a minimum period of time of five minutes per activity as the minimum standard for that activity to be beneficial for health, even though the authors recognize that every short bouts of PA (taking the stairs instead of the elevator for example) can have a beneficial effect. Frequency and regularity are, in fact, essential for health (Lustyk et al. 2004, Musich et al. 2017). For example, three short 5-minute walks a day five times a week (total duration of 75 minutes) are more efficient than one 2-hour walk only once a week. On the other hand, excessive duration for a PA session might have negative effects on health (Zhu et al. 2019). The duration of each PA session should provide the person with a well-being feeling and allow him/her to fulfill his/her normal daily activities. A gradual increase of PA-session duration helps prevent possible overuse injuries (Brenner and the Council on Sports Medicine and Fitness 2007).

\section{Physical Activity Type}

In Team Pentathlon, one main objective of the program is to help students recognize differences in levels and type of activity performed to correctly assess benefits on physical health. Weighting the PA type into four groups according to the average level of energy expenditure while performing the activity, and thus influencing the calculation of Pentathlon Hours (PH), is a way to help students understand differences between and within activities. Moreover, cardiovascular activities such as running might also be practiced at different paces which would lead to different effects on health depending on the intensity in which they are performed. Finally, understanding the difference and differential impact on health/fitness between types of activities, such as team sports or muscular activities, probably is one of the most important knowledge for adopting a healthy and active lifestyle (Acree et al. 2006). 
The determination of four intensity-levels of physical utilitarian and leisure activities to create a PAP index for older students and adults is based on the work of Martel et al. (2011) on the Team Pentathlon. This led the authors of the present article to defining a unit of measurement named Physical-Activity-Practice Corrected Hour (PAP-CH). The simplicity of the calculation of such an index should make it easier for more adults to determine their level of PA practice. However, as alluded to earlier and also stated by Ryan and Deci (2020), individuals must establish their own PAP-CH standard based on their life context rather than simply seek to achieve a "one size fits all" standard.

Unlike Martel et al. (2011), who restrain students to certain type of activities, the authors consider it important trying to include all forms of PA in the calculation of the adult-oriented PAP index instead of limiting the monitoring to PAs done by younger students. Activities are classified into four intensity levels based on MET values as determined by the Compendium of Physical Activities (Ainsworth et al. 2011) for each type of activity (see Table 1A for instance). PAs involving different levels of energy expenditure are assigned different correction factors: 10.0 METs or more get a corrected value of 1.00; 6.0 to 9.9 METs have a corrected value of $0.75 ; 4.00$ to 5.99 METs get a 0.5 -correction value; finally, 2.5 to 3.99 METs get a 0.25 -correction value. Readers will note that activities with a requirement of less than 2.5 METs are not considered in the calculation of the PAP index since they are considered too low on energy expenditure for improving physical fitness.

Table 1A. Aquatic Activities: Intensity Levels* and Corresponding Correction Factors for PAP Index

\begin{tabular}{|c|c|c|c|}
\hline $\begin{array}{c}2.5 \text { to } 3.99 \text { METs } \\
(0.25)\end{array}$ & $\begin{array}{c}4.00 \text { to 5.99 METs } \\
(0.50)\end{array}$ & $\begin{array}{c}\text { 6.0 to 9.9 METs } \\
(0.75)\end{array}$ & $\begin{array}{c}\text { 10.0 METs and over } \\
(1.00)\end{array}$ \\
\hline $\begin{array}{l}\text { Canoeing, rowing } \\
\text { light effort } \\
\text { Swimming, treading } \\
\text { water, moderate effort, } \\
\text { general } \\
\text { Diving, springboard or } \\
\text { platform } \\
\text { Sailing, } \\
\text { Windsurfing light } \\
\text { Water volleyball }\end{array}$ & $\begin{array}{l}\text { Paddle boat } \\
\text { Swimming, } \\
\text { leisurely, not lap } \\
\text { swimming, general } \\
\text { Canoeing, rowing } \\
\text { moderate effort } \\
\text { Swimming laps, } \\
\text { freestyle, front } \\
\text { crawl, slow, light } \\
\text { or moderate effort } \\
\text { Water walking, } \\
\text { moderate effort, } \\
\text { moderate pace }\end{array}$ & $\begin{array}{l}\text { Swimming, crawl, } \\
\text { fast speed, 75 } \\
\text { yards/minute, } \\
\text { vigorous effort } \\
\text { Water polo } \\
\text { Skindiving, scuba } \\
\text { diving, general } \\
\text { Water walking, } \\
\text { vigorous effort, brisk } \\
\text { pace }\end{array}$ & $\begin{array}{l}\text { Swimming, butterfly, } \\
\text { general } \\
\text { Canoeing, Rowing, } \\
\text { kayaking, competition, } \\
>6 \text { mph, vigorous effort } \\
\text { Windsurfing or } \\
\text { kitesurfing } \\
\text { Swimming, } \\
\text { breaststroke training or } \\
\text { competition }\end{array}$ \\
\hline
\end{tabular}

*Adapted from Ainsworth et al. (2011).

Activities were assembled into six groups as follows: (a) aquatic activities; (b) team sports and games; (c) endurance (aerobic) activities; (d) individual sports and games or artistic activities; (e) dual sports and games; and (f) calisthenics and muscular activities. Activities listed in Tables $1 \mathrm{~A}$ to $1 \mathrm{~F}$ serve to illustrate different intensity levels of PA practice according to each group of exercise. A comprehensive listing of all potential physical activities would be beyond the scope of this article. Readers can draw on these activities to determine which group would better suit a non-listed activity. For example, a person who gardens 
45 minutes every day may consider this activity to be within the Calisthenics and muscular activities group (Table 1F), at a 0.25 -correction level.

Table 1B. Team Sports and Games: Intensity Levels* and Corresponding Correction Factors for PAP Index

\begin{tabular}{|c|c|c|c|}
\hline $\begin{array}{c}2.5 \text { to } 3.99 \text { METs } \\
(0.25)\end{array}$ & $\begin{array}{c}4.00 \text { to } 5.99 \text { METs } \\
(0.50)\end{array}$ & $\begin{array}{c}6.0 \text { to } 9.9 \text { METs } \\
(0.75)\end{array}$ & $\begin{array}{c}\text { 10.0 METs } \\
\text { and over } \\
(1.00)\end{array}$ \\
\hline $\begin{array}{l}\text { Volleyball, non- } \\
\text { competitive, } 6 \text { - 9- } \\
\text { member team, general } \\
\text { Frisbee playing, general } \\
\text { Croquet } \\
\text { Softball, practice } \\
\text { Coaching, football, } \\
\text { soccer, basketball, } \\
\text { baseball, swimming, } \\
\text { etc. } \\
\text { Curling } \\
\text { Football, touch, flag, } \\
\text { light effort }\end{array}$ & $\begin{array}{l}\text { Basketball, non- } \\
\text { game, general } \\
\text { Basketball, } \\
\text { shooting baskets } \\
\text { Volleyball, } \\
\text { competitive, in } \\
\text { gymnasium } \\
\text { Softball or Baseball }\end{array}$ & $\begin{array}{l}\text { Ice Hockey competitive } \\
\text { Soccer, competitive } \\
\text { Basketball competitive } \\
\text { Football, competitive } \\
\text { Flag football } \\
\text { Ultimate frisbee } \\
\text { Handball competitive } \\
\text { Lacrosse } \\
\text { Beach volleyball } \\
\text { Field hockey } \\
\text { Rugby }\end{array}$ & \\
\hline
\end{tabular}

*Adapted from Ainsworth et al. (2011).

Table 1C. Endurance (Aerobic) Activities: Intensity Levels* and Corresponding Correction Factors for PAP Index

\begin{tabular}{|c|c|c|c|}
\hline $\begin{array}{c}2.5 \text { to 3.99 METs } \\
(0.25)\end{array}$ & $\begin{array}{c}4.00 \text { to } 5.99 \text { METs } \\
(0.50)\end{array}$ & $\begin{array}{c}6.0 \text { to } 9.9 \text { METs } \\
(0.75)\end{array}$ & 10.0 METs and over \\
\hline $\begin{array}{l}\text { Bicycling, leisure } \\
\text { Stair climbing, } \\
\text { slow pace } \\
\text { Walking, to work } \\
\text { or class or for } \\
\text { pleasure } \\
\text { Video exercise } \\
\text { workouts, TV } \\
\text { conditioning } \\
\text { programs (e.g., } \\
\text { cardio-resistance), } \\
\text { moderate effort }\end{array}$ & $\begin{array}{l}\text { Bicycling, moderate } \\
\text { pace } \\
\text { Rowing, stationary } \\
\text { ergometer, general, } \\
\text { vigorous effort } \\
\text { Elliptical trainer, } \\
\text { moderate effort } \\
\text { Stationary bicycling } \\
\text { light-to-moderate } \\
\text { effort } \\
\text { Aerobic, step, low } \\
\text { impact } \\
\text { Jog/walk } \\
\text { combination } \\
\text { Walking, } 3.5 \text { mph, } \\
\text { brisk speed, not } \\
\text { carrying anything } \\
\text { Hiking, cross } \\
\text { country } \\
\text { Skating, moderate } \\
\text { effort }\end{array}$ & $\begin{array}{l}\text { Bicycling, vigorous } \\
\text { effort Mountain } \\
\text { bicycling, general } \\
\text { Stair-treadmill } \\
\text { ergometer, general } \\
\text { Health club } \\
\text { conditioning classes } \\
\text { Rowing, stationary, } \\
\text { moderate effort } \\
\text { Cross country } \\
\text { skiing moderate } \\
\text { effort } \\
\text { Aerobic, general } \\
\text { Running, cross } \\
\text { country } \\
\text { Jogging, general } \\
\text { Roller Skating } \\
\text { Walking for } \\
\text { exercise fast pace }\end{array}$ & $\begin{array}{l}\text { Bicycling, mountain, } \\
\text { competitive, racing } \\
\text { Stationary bicycling } \\
\text { very vigorous effort } \\
\text { Running, } 10 \mathrm{~km} / \mathrm{h} \text { and } \\
\text { faster } \\
\text { Rollerblading, In-line } \\
\text { skating, } 24.0 \mathrm{~km} / \mathrm{h} \\
\text { maximal effort } \\
\text { Rope jumping, fast } \\
\text { pace, } 120-160 \\
\text { skips } / \text { min } \\
\text { Speed skating } \\
\text { competitive } \\
\text { Cross-country skiing, } \\
\text { skating }\end{array}$ \\
\hline
\end{tabular}

*Adapted from Ainsworth et al. (2011). 
Table 1D. Individual Sports and Games or Artistic Activities: Intensity Levels* and Corresponding Correction Factors for PAP Index

\begin{tabular}{|c|c|c|c|}
\hline $\begin{array}{c}2.5 \text { to } 3.99 \text { METs } \\
(0.25)\end{array}$ & $\begin{array}{c}4.00 \text { to } 5.99 \text { METs } \\
(0.50)\end{array}$ & $\begin{array}{c}\text { 6.0 to 9.9 METs } \\
(0.75)\end{array}$ & $\begin{array}{c}\text { 10.0 METs and } \\
\text { over } \\
(1.00)\end{array}$ \\
\hline $\begin{array}{l}\text { Hacky sack } \\
\text { Juggling } \\
\text { High ropes course, } \\
\text { multiple elements } \\
\text { Gymnastics, } \\
\text { general } \\
\text { Golf, using power } \\
\text { cart } \\
\text { Trampoline, } \\
\text { recreational } \\
\text { Bowling } \\
\text { Tai chi, qi gong, } \\
\text { general } \\
\text { Archery, non- } \\
\text { hunting } \\
\text { Track and field } \\
\text { (e.g., shot, discus, } \\
\text { hammer throw) }\end{array}$ & $\begin{array}{l}\text { Dance, ballet, } \\
\text { modern, or jazz, } \\
\text { general } \\
\text { Golf walking, } \\
\text { pulling/carrying } \\
\text { clubs } \\
\text { Skateboarding, } \\
\text { competitive, } \\
\text { vigorous effort } \\
\text { Track and field (e.g., } \\
\text { high jump, long } \\
\text { jump, triple jump, } \\
\text { javelin, pole vault) } \\
\text { Rock climbing, } \\
\text { ascending or } \\
\text { traversing rock, low- } \\
\text { to-moderate } \\
\text { difficulty } \\
\text { Boxing, punching } \\
\text { bag }\end{array}$ & $\begin{array}{l}\text { General dancing } \\
\text { (e.g., disco, folk, } \\
\text { Irish step dancing, } \\
\text { line dancing, polka, } \\
\text { contra, country, } \\
\text { ballet, modern, or } \\
\text { jazz, performance, } \\
\text { vigorous effort) } \\
\text { Track and field } \\
\text { (e.g., steeplechase, } \\
\text { hurdles) } \\
\text { Orienteering } \\
\text { Boxing, sparring }\end{array}$ & $\begin{array}{l}\text { Ballroom dancing, } \\
\text { competitive, } \\
\text { general } \\
\text { Boxing, in ring, } \\
\text { general }\end{array}$ \\
\hline
\end{tabular}

*Adapted from Ainsworth et al. (2011).

Table 1E. Dual Sports and Games: Intensity Levels* and Corresponding Correction Factors for PAP Index

\begin{tabular}{|c|c|c|c|}
\hline $\begin{array}{c}2.5 \text { to 3.99 METs } \\
(0.25)\end{array}$ & $\begin{array}{c}4.00 \text { to 5.99 METs } \\
(0.50)\end{array}$ & $\begin{array}{c}6.0 \text { to } 9.9 \text { METs } \\
(0.75)\end{array}$ & $\begin{array}{l}\text { 10.0 METs and } \\
\text { over } \\
(1.00)\end{array}$ \\
\hline & $\begin{array}{l}\text { Fencing } \\
\text { Paddleball, casual, } \\
\text { general } \\
\text { Tennis, doubles } \\
\text { Wrestling } \\
\text { Badminton, social } \\
\text { singles and doubles, } \\
\text { general } \\
\text { Martial arts, } \\
\text { different types, } \\
\text { slower pace, novice } \\
\text { performers, practice } \\
\text { Tennis, hitting balls, } \\
\text { non-game play, } \\
\text { moderate effort }\end{array}$ & $\begin{array}{l}\text { Paddleball, } \\
\text { competitive } \\
\text { Racquetball, } \\
\text { competitive } \\
\text { Tennis, singles } \\
\text { Boxing, sparring } \\
\text { Squash, general } \\
\text { Badminton, } \\
\text { competitive } \\
\text { Racquetball, general }\end{array}$ & $\begin{array}{l}\text { Boxing, in ring, } \\
\text { general } \\
\text { Racquet sports } \\
\text { competitive } \\
\text { Jai alai } \\
\text { Martial arts, } \\
\text { different types, } \\
\text { moderate pace (e.g., } \\
\text { judo, jujitsu, karate, } \\
\text { kick boxing, tae } \\
\text { kwan do, tai-bo, } \\
\text { Muay Thai boxing) }\end{array}$ \\
\hline
\end{tabular}

*Adapted from Ainsworth et al. (2011). 
Table 1F. Calisthenics and Muscular Activities: Intensity Level*s and Corresponding Correction Factors for PAP Index

\begin{tabular}{|c|c|c|c|}
\hline $\begin{array}{c}2.5 \text { to } 3.99 \text { METs } \\
(0.25)\end{array}$ & $\begin{array}{c}4.00 \text { to } 5.99 \text { METs } \\
(0.50)\end{array}$ & $\begin{array}{c}\text { 6.0 to 9.9 METs } \\
(0.75)\end{array}$ & $\begin{array}{l}\text { 10.0 METs } \\
\text { and over } \\
(1.00)\end{array}$ \\
\hline $\begin{array}{l}\text { Video exercise } \\
\text { workouts, TV } \\
\text { conditioning programs } \\
\text { moderate effort } \\
\text { Yoga, Power } \\
\text { Activity promoting } \\
\text { video game (e.g., Wii } \\
\text { Fit), moderate effort } \\
\text { Calisthenics (e.g., } \\
\text { push-ups, sit ups, pull- } \\
\text { ups, lunges), light or } \\
\text { moderate effort } \\
\text { Home exercise, } \\
\text { general } \\
\text { Resistance (weight) } \\
\text { training, multiple } \\
\text { exercises, 8-15 } \\
\text { repetitions at varied } \\
\text { resistance } \\
\text { Pilates, general } \\
\text { Therapeutic exercise } \\
\text { ball, Fit Ball exercise }\end{array}$ & $\begin{array}{l}\text { Resistance training } \\
\text { (weightlifting, free } \\
\text { weight, nautilus or } \\
\text { universal), power } \\
\text { lifting or body } \\
\text { building, vigorous } \\
\text { effort } \\
\text { Video exercise } \\
\text { workouts, TV } \\
\text { conditioning } \\
\text { programs (e.g., } \\
\text { cardio-resistance), } \\
\text { vigorous effort } \\
\text { Health club exercise, } \\
\text { general } \\
\text { Army type obstacle } \\
\text { course exercise, boot } \\
\text { camp training } \\
\text { program, resistance } \\
\text { (weight) training, } \\
\text { circuit training, } \\
\text { moderate effort }\end{array}$ & $\begin{array}{l}\text { Calisthenics (e.g., } \\
\text { push-ups, sit ups, } \\
\text { pull-ups, jumping } \\
\text { jacks), vigorous } \\
\text { effort } \\
\text { Circuit training, } \\
\text { including kettlebells, } \\
\text { vigorous intensity } \\
\text { Health club exercise, } \\
\text { conditioning classes } \\
\text { Activity promoting } \\
\text { video/arcade game } \\
\text { vigorous effort }\end{array}$ & \\
\hline
\end{tabular}

*Adapted from Ainsworth et al. (2011).

Diversity

Performing regularly different forms of physical activity rather than just one brings many benefits to overall health (Mäkelä et al. 2017). In the Team Pentathlon, the learning notion of diversity was incorporated through the rules by asking each team to collectively try to achieve a minimum PH value in all five PA types, based upon the most frequent physical activities practiced by students (aquatics; team sports; cyclic [aerobic] activities; physical conditioning activities; individual or dual sports (Gagnon et al. 2021)). As is the case for younger people, research showed that multiplying types of activities incorporated to lifestyle, thus not only specific to seasonal conditions, provides overload stimulations for the heart, muscles, proprioceptive system and balance, or flexibility and agility, helps adults to continue improving their health, and counteracts the stagnation or capping effect that we find when somebody practices only one PA at the same intensity (Bompa 1999). For example, doing five hours of activity per week using three different types of PA (e. g., cardiovascular, muscular and aquatics) would be considered better for overall health than the same volume of activity performed with only one type of activity. Thus, the authors submit that activities such as active transportation, gardening or physical work should be included in any PAP assessment for adults, provided they are performed at a satisfactory level of intensity. 
Computing the Physical Activity Practice Index

A simple calculation formula for determining a weekly PAP index might have been as follows: $(\mathbf{F} \times \mathbf{D}) / 60 \times \mathbf{c}$, where $\mathbf{F}$ represents the number of PA sessions per week, $\mathbf{D}$ represents the duration of each PA session in minutes, and $\mathbf{c}$ represents the correction factor for the activity concerned. However, individuals' lifestyle will not always be so systematic as to allow the use of such a straightforward formula. The very fact that the duration of PA sessions may well vary from day to day, or even from one session to another within a single day, makes it impossible to compute adequately a weekly PAP-CH volume through the use of F x D. Also, the selection of various types of activity precludes the use of a unique correction coefficient. Whenever an individual wishes to monitor his/her PAP level, the suggested procedure is then to record, for each PA session, the type and category of activity performed and its duration in minutes, considering any change of activity as the start of a new PA session. Keeping a log of all distinct sessions performed throughout the week will then make it possible for the person to compute a partial PAP index for each of the four intensity levels as follows: (total duration [min] over all PA session concerned $\mathrm{x}$ correction factor)/60, yielding a result in term of PAP-CHs (see bottom of each level column in Table 2).

Table 2. Summary Log and Computation of the PAP Index* (PAP-CHs): An Example

\begin{tabular}{|c|c|c|c|c|c|}
\hline \multicolumn{6}{|c|}{ Type of Activity and Duration (D, min) for Each Intensity-Level and Correction Factor } \\
\hline Category & Level $1(0.25)$ & Level $2(0.50)$ & Level $3(0.75)$ & Level 4 (1.0) & Total \\
\hline Day & Type/Duration & Type/Duration & Type/Duration & $\begin{array}{c}\text { Type/Duratio } \\
n\end{array}$ & \\
\hline $\begin{array}{l}\text { Day 1: December } \\
7^{\text {th }} \\
\text { Su MT W Th F S }\end{array}$ & Walking/35 & & Calisthenics/20 & Running/45 & \\
\hline $\begin{array}{l}\text { Day 2: December } \\
8^{\text {th }} \\
\text { Su M T W Th F S }\end{array}$ & Walking/35 & & & & \\
\hline $\begin{array}{l}\text { Day 3: December } \\
9^{\text {th }} \\
\text { Su M T W Th F S }\end{array}$ & Walking/37 & & & Running/62 & \\
\hline $\begin{array}{l}\text { Day 4: December } \\
10^{\text {th }} \\
\text { Su M T W Th F S }\end{array}$ & $\begin{array}{l}\text { Walking } \\
(\text { am }) / 20 \\
\text { Walking } \\
(p m) / 20\end{array}$ & & & & \\
\hline $\begin{array}{l}\text { Day 5: December } \\
11^{\text {th }} \\
\text { Su M T W Th F S }\end{array}$ & Walking/40 & & Calisthenics/20 & Running/35 & \\
\hline $\begin{array}{l}\text { Day 6: December } \\
12^{\text {th }} \\
\text { Su M T W Th F S }\end{array}$ & & & & & \\
\hline $\begin{array}{l}\text { Day 7: December } \\
13^{\text {th }} \\
\text { Su M T W Th F S }\end{array}$ & $\begin{array}{c}\text { Alpine } \\
\text { skiing/240 }\end{array}$ & & & & \\
\hline Total (min) & 427 & & 40 & 142 & 609 \\
\hline Total (C-min) & 107 & & 30 & 142 & 279 \\
\hline Total CHs & 1.78 & & 0,5 & 2.37 & $* 4.65$ \\
\hline
\end{tabular}

${ }^{1}$ In left column, put a mark on or circle appropriate weekday as a reference. 
Summing up the four partial PAP indices (see bottom row of Table 2) will provide the person with the appropriate week PAP index (total number of PAP$\mathrm{CHs}$ ). The computation formula for the PAP index may thus be expressed as follows:

PAP index (PAP-CHs) $=\sum_{\mathrm{L} 1}^{\mathrm{L} 4} \underset{\mathrm{S} 1}{[}\left(\sum\right.$ duration of S min. $)$ x c $\left./ 60\right]$

where S: any activity session.

S1: activity session \#1 of the week for a particular level.

Sx: last activity session of the week for that particular level.

c: correction factor for the intensity level concerned.

L1: intensity level $1(\mathbf{c}=0.25)$.

L4: intensity level $4(\mathbf{c}=1.00)$.

Reflecting on the data used to compute the index, the person can then appreciate the extent to which principles of frequency, duration and diversity were applied. Table 2 illustrates an example of a person who recorded the PAP-related data during one week in order to compute his/her PAP index. There is no doubt it would be relatively easy to develop an application to compute electronically one's PAP index. However, the log illustrated in Table 2 provides much information for individuals to reflect on their PAP profile instead of having a global and less discriminate feedback. For instance, with regard to Table 2 results, readers will note that the person's jogging activity, performed on three occasions, accounts for $23 \%$ of the weekly PA volume but for $51 \%$ of the total PAP-CHs cumulated. Diversity is illustrated by the use of four different activities at three different levels of intensity.

\section{Regulation of Physical Literacy Levels}

"Know thyself" said Socrates. With regard to one's PL awareness and PAP regulation, this advice seems appropriate, particularly when adults are concerned. Stories of individuals who pay a fee for registering into a 2 or 3-month fitness program and give up after a few weeks, ending up losing their money, are not rare. Perhaps because of a lack of knowledge, PL awareness and reflection on their PA habits, many people enter a fitness program, or some other PA program, on a whim and end up giving up.

Earlier, while discussing the computation of the PAP index, the authors identified several characteristics of one's PA practice such as frequency, duration, intensity, type of activity. Related constructs also identified were volume and diversity. All of these features may be subjected to regulation. First, from a quantitative point of view, we will consider that PA volume and PA intensity are central elements in the computation of the index. These are therefore potential elements to be considered when performing what we might call quantitative PAP regulation. Obviously, frequency and duration have a direct impact on PA volume, 
but they may also be reflected on from a qualitative point of view in the sense that an individual may, for a same raw PA volume result, choose several frequency/ duration combinations based on particular agenda preferences or constraints. We have also mentioned that beyond the simple amount of physiological stress or energy expenditure related to one's PAP, diversity ought to be considered, thus adding a qualitative element to PAP regulation.

Discussing the regulation of tactical learning in team sports, Godbout and Gréhaigne (2020) reviewed and differentiated the processes of self-regulation, teacher-centered co-regulation, student/peer-centered co-regulation, shared regulation, and socially shared regulation. Such constructs do apply to PL development or maintenance as well. Also, analogically to the case of team sports, one may consider that planning PAP projects on a long-term (season) and/or short term (days/weeks) basis necessitates strategic and tactical choices, based on various constraints that impose on active people, considering that permanent constraints such as handicaps or physical impairments can no longer be a factor in varying strategic choices, nor tactical ones.

\section{How Much Physical Activity Is Enough?}

Whatever may be the PAP level of an individual, any PA is better than none. However, given the perspective of this article, what is at stake is the impact of regular physical activity on his/her physical fitness, health, and well-being status. Thus, it is from the start admitted that, as mentioned earlier, activities associated with too low-energy expenditure are not to be considered for the computation of the PAP index. That being said, there remains the matter of PA dosage, that is the PA volume performed within a given reference period of time, considering the intensity level of the performance. According to the U.S. Department of Health and Human Services (2018), adults should do at least 2.5 to 5.0 hours a week of moderate-intensity, or 1.25 to 2.50 hours a week of vigorous-intensity aerobic physical activity, or an equivalent combination of moderate- and vigorousintensity aerobic activity. Preferably, aerobic activity should be spread throughout the week. Referring to the PAP index discussed in this article, the " 1.25 to 2.50 hours of vigorous-intensity aerobic physical activity" target would correspond to 1.25 to 2.50 PAP-CHs, not counting the time devoted to other types of activity. In relation with the principle of diversity alluded to earlier, the U.S. Department of Health and Human Services $(2018$, p. 8) recommended that "adults should also do muscle-strengthening activities of moderate or greater intensity and that involve all major muscle groups on 2 or more days a week, as these activities provide additional health benefits".

\section{Physical Literacy Awareness}

Along one individual's PL journey, all types of regulation mentioned above may be put to use. On the long run, the goal for an adult is a functional PL awareness and PL self-regulation; that person will have become "self-directing and self-actualizing" (Klesius 1971, p. 47). Whereas metacognitive awareness 
makes one understand the way(s) he/she tends to operate in a learning environment, PL awareness makes someone take notice of the rapport one has with physical activity, its meaning, its importance for the sake of pleasure and/or health benefits, its frequency, its intensity, its duration, its total volume, its diversity, in a word its profile.

Discussing the four target areas for assessing PL, Robinson and Randall (2017) illustrated four PL elements to be considered: (a) physical competence; (b) knowledge and understanding; (c) motivation and confidence; and (d) lifetime engagement. PL regulation implies awareness of each of these elements:

- Awareness of one's physical competence means that the individual is conscious of the spectrum of physical activities he/she can perform efficiently and safely.

- Awareness of one's knowledge and understanding means that the individual knows to what extent he/she understands the principles of regular PA regarding the FITT formula, the acute and chronic effects of exercise, etc.

- Awareness of one's motivation means that the individual understands the reasons for his/her engagement into PA and the factors that influence positively or negatively such an engagement.

- Awareness of one's PA engagement (or PAP) means that the individual is conscious of the level of his/her regular engagement into PA.

Physical competence, knowledge and motivation all contribute to a life engagement in regular PA, the core of PL. As mentioned earlier, this article is primarily devoted to PAP awareness and regulation, although a few remarks are hereafter presented with respect to the matter of motivation.

\section{Regular Physical Activity Practice and Motivation}

Why would one want to regulate his/her PAP level once schooling is over or if there is no grade attached? One's regular PAP at a health level often rests on motivation, one of the PL elements alluded to earlier. Citing a recent publication from Participation Action, Robinson and Randall (2017, p. 44) quoted "Motivation is described in the consensus statement as 'enthusiasm for, enjoyment of, and selfassurance in adopting physical activity as an integral part of life"'. With all due respect to authors concerned, considering what has been written on the subject of motivation with regard to PAP, this vision of motivation is far too restricted. Intrinsic and extrinsic motivation are well recognized constructs in the literature (Ryan and Deci 2020). It is not in the scope of this article to develop on the subject of PAP motivation. However, it seems appropriate to draw readers' attention on a few motivation-related factors.

"Technically intrinsic motivation pertains to activities done 'for their own sake,' or for their inherent interest and enjoyment.... [such activities] are not dependent on external incentives or pressure, but rather provide their own satisfactions and joys" (Ryan and Deci 2020, p. 3). Leisure physical activities 
likely meet closely that operational definition of intrinsic motivation. A particular factor of intrinsic motivation, surprisingly often overlooked, is the endorphin factor. It is a well-known fact that when performed at a significant intensity level, physical activity of the endurance type (like jogging, cycling, or cross-country skiing for instance) might bring about a bodily production of endorphin, a substance conducive to pleasure and well-being. The effect of that physical-effort induced hormone may not be noticeable at first but, as regular PAP sets in, the performer starts feeling an addiction effect, a potent intrinsic-motivation element. Regularly active individuals, when deprived of PA, display signs of withdrawal as a way of expressing their need for further PA.

For its part, extrinsic motivation relates to a heterogeneous category of PA behaviors done for reasons other than their inherent satisfaction. This, however, does not necessarily mean that individuals espouse such behaviors forcibly. If one excludes situations in which one exercises under the pressure of external rewards, punishments, compliance or reactance, Ryan and Deci (2017) have identified three levels of internalized extrinsic motivation: introjection (e.g., approval from self and others); identification (e.g., conscious valuing of activity); integration (e.g., congruence, that is making one's own whatever motive induces one individual to exercise). Whatever the reason(s) for which one individual becomes or keeps physically active, reflection on one's PA practice should take into account an awareness of such motives in view of an authentic regulation (meaning making choices for the good reasons). For instance, extrinsic motivation, with regard to PAP, may rest on (a) family/peer/social environment pressure, (b) knowledge about beneficial effects of regular PAP, (c) health or fitness maintenance, (d) health rehabilitation, (e) physical appearance, (d) seduction, etc.

Discussing the debate-of-ideas as a particular strategy for regulating tactical learning in team sports, Godbout and Gréhaigne (2020) have drawn readers' attention on the possible impact of learners' field-dependence (FD) or fieldindependence (FI) level as to what extent they may be influenced by their physical and social environment. Reviewing the literature on field dependency/ independency theory, Liu and Chepyator-Thomson (2009, p. 126) wrote:

FD individuals have a tendency to rely on, and are influenced by, external referents (environments, authorities, and significant others), and function less autonomously in decision-making and behaviors. In contrast, FI individuals tend to rely on internal referents (self) as the primary source for, and are more autonomous in, decisionmaking and behaviors, have a more articulated body concept, and are more sensitive to body information.

These characteristics are basically similar to those expressed by Angeli and Valanides (2012), Holmes et al. (2013), Woodbridge (1995), and Woodbridge and Haimes-Bartolf (2006). Although it is not the purpose of this article to discuss the possible relationship between individuals' FD/FI level and their PAP motivation, it seems reasonable to hypothesize that, referring to Ryan and Deci's (2020) taxonomy of motivation briefly described earlier, FD older students' and adults' motivation will tend to be "externally" or "somewhat externally" regulated. For its part, FI older students' and adults' motivation will tend to be "somewhat- 
internally" or internally regulated. In other words, likely FI individuals will tend to manage their PAP on their own while likely FD individuals will tend to rely on others to maintain a regular PAP. Particulars of both categories may of course vary due to a series of other factors. Coming back to the "awareness of PAP motivation" as operationally defined earlier, the point for an older student or an adult (whatever his/her age) is to reflect on his/her PAP level and PA profile, and identify which domestic, financial, environmental and social conditions tend to induce him/her into a higher level of PAP. Should individuals be able to answer such question(s), then they can proceed to plan realistic specific PA projects and their PAP in general.

\section{Physical Activity Practice Awareness and Regulation Scenarios}

One may wonder what the point behind the notion of a PA project is. The very notion of "project" is closely linked to that of regulation. Left to haphazard, one's PAP will likely wither, on and off, without taking root. Strategy wise, making choices for the planning of a several-week PA project (one-semester or one-season long for instance) implies bearing in mind several elements that do not necessarily pertain to the same domain. Above all, decisions will take into account economic constraints. With regard to outdoor activities, environment constraints or opportunities will play an important role in selecting preferred activities; so will seasonal constraints. Time and fitness constraints, with respect to the FITT formula components, will also help specify the particular profile of the PA project: such types of exercises, so many times a week, for such a duration, at such intensity.

With regard to PAP regulation, the obvious goal is to have the new adult take charge of the planning and enacting of a regular practice of physical activity, with or without the participation to fitness programs offered in the community. Autonomy and self-reliance as to one's PAP do not come overnight as does the legal age of majority. Awareness of one's level of PL and its regulation need to be nurtured before the end of the schooling period as part of the PE curriculum (see Whitehead (2013b), Table 1, on page 54). PL awareness means, among other elements mentioned earlier, being conscious of one's PAP level, a state of mind that does not come offhand. Perkins' (1992) level categories for metacognitive awareness could be useful for operationalizing four degrees of PL awareness: tacit, aware, strategic, and reflective. Tacit physical literates are individuals who may exercise without really thinking about it, matter-of-factly. Aware physical literates are conscious of the fact they perform physical activities for one reason or another. Strategic physical literates organize their PAP, taking into account the time at their disposal, their preferences in term of activities, the cost, etc., and making decisions accordingly. Finally, reflective physical literates, beyond being strategic about their PAP, also reflect on their PA profile and regulate their PA planning/project.

Throughout the PL journey, other regulation scenarios, in addition to PL selfregulation, may be envisioned. Co-regulation will occur when two individuals are involved in the regulation process. Teacher/expert-centered co-regulation may involve a teacher with a particular student under the form of feedbacks and/or 
particular instructions for following activity sessions, or involve an expert (fitness consultant, fitness leader, private dance teacher, etc.) with an adult who has elected to register in some fitness or dance class, for instance. Student/peer-centered coregulation may involve student dyads checking on one another, conducting simultaneously their particular PE-related PL project; they may then discuss their respective FITT formula, exercise together, etc., the point being that there is no more-competent/less-competent rapport among them. They co-regulate their respective PAP on equal terms. The same kind of connection may be seen between adults (friends, spouses, family members). Finally, socially shared PAP regulation will occur when groups of individuals (students or adults) accept or choose to exercise as a group, monitor their PAP profile and make decisions as to a common PAP project for coming days or weeks. Although each member of the group selfregulates in order to participate fully, he/she is committed to apply the common PAP project. PE classes, civil sport leagues, fitness groups, dance companies, etc., may be involved in this type of regulation.

With regards to the practice of team sports, Gréhaigne and Godbout (1995, p. 491) have distinguished the notions of strategy and tactics: “... strategy refers to these elements discussed in advance in order for the team to organize itself. Tactics are a punctual adaptation to new configurations of play and to the circulation of the ball; they are therefore an adaptation to opposition". A few years later, they added a few clarifications (Gréhaigne et al. 1999, p. 168): "There is a fundamental difference between strategy and tactics as far as their relationship with time is concerned. Strategy is associated with more elaborate cognitive processes as the decisions made are based on reflection without time constraints. Tactics operate under strong time constraints". Analogically, one may consider that for an individual, planning or adjusting his/her PA project over days, weeks and months bears a resemblance with planning and enacting a strategic match plan. In terms of long-term PA profiling, PAP remains a relatively linear experience in the sense that individuals may very well make strategic PA plans for a whole season, or even a whole year given appropriate seasonal conditions or continuous indoor access. On a short-term basis, one's PA schedule may prove to be more nonlinear, based on varying weather conditions, injuries, sickness episodes, work-based travels, family chores, etc. Such nonlinear conditions call for tactical choices, the individual adjusting temporarily his/her PA profile or daily schedule, keeping in mind the targeted PAP index. One may hypothesize that FI individuals will likely adjust more easily to such constraints.

As described earlier, PL awareness involves being conscious not only of one's PA engagement level but also of one's physical competence, knowledge and understanding, and motivation. The more physically literate is an individual, the easier it becomes to strategically plan alternative PAP scenarios and to adjust to unexpected constraints. PA tactical adjustments, fueled by intrinsic or internalized extrinsic motivation, may call for considering physical and or social environmentrelated opportunities, selecting other physical activities, while maintaining a volume of activity that meets one's pre-stablished FITT formula. The more physically competent, knowledgeable and motivated the individual, the easier it gets to adjust to constraints. 


\section{Tailored Physical-Activity-Practice Monitoring for More Engaged Physical Literates}

The PAP index computed on the basis of the procedure described earlier in this article is intended for individuals who wish to benefit from a general indicator of their level and quality of PA engagement. It is likely that as individuals exercise regularly (particularly younger adults), their work capacity will increase so that an activity classified as vigorous at first may become moderate for them after a while. Some individuals may wish to plan their PA project on the basis of a more precise criterion in term of cardio-respiratory intensity, not being satisfied with the general and average classification presented in this article. In such cases, intensity may be determined in terms of percentage of estimated maximal heart rate or, even better, percentage of heart rate reserve. It is not the purpose of this article to describe at length the relationship between maximum working capacity, activity-related energy expenditure and heart rate associated with percentages of $\mathrm{VO}^{2}$ max. Simple procedures for computing either a given percentage of estimated maximal heart rate or a given percentage of heart rate reserve may be found in textbooks (e.g., Corbin et al. 2018) or on the web (e.g., Corbin et al. 2014), as well as recommended percentage values for moderate, vigorous or very vigorous levels of activity. Concerning activities more oriented toward muscular fitness, they may choose to exercise based on percentages of maximum strength and, for instance, on a Likert scale appreciation for other types of activities. Tidén et al. (2021) have used a "getting sweaty and out of breath" criterion as an appreciation of PA intensity that would, in our mind, put an activity at level 3 or 4 (Table 2).

In recent years, technological advances related to smart mobile devices have made it possible to inform adult participants about their PAP level (Dunn et al. 2018). Whether on smartwatches or cell phones, these applications can calculate movements (GPS, accelerometer or pedometer), provide daily reminders of the level of practice and warn the participant when the PAP level is lower than usual. Some of these devices can even simultaneously take heart rate or even blood pressure during exercise and store those data for future use. Systematic reviews showed that the effectiveness of these apps to stimulate PA is for a short period of time (Pradal-Cano et al. 2020, Romeo et al. 2019). Unfortunately, these devices have certain limitations and cannot, for example, calculate all forms of PA, such as those that do not require displacement (muscular activities for example). As these technologies are getting more accessible to the general public and are effortless in terms of entering daily results, they become interesting options for someone who wants to regulate his/her PA practice.

\section{Limitations}

The procedure presented in this article is not intended to accurately measure individuals' level of PA practice. It should be looked at as simple monitoring instrument that individuals can use to understand the main principles of a healthy 
PAP, to regulate their PA practice and develop their physical literacy. Several elements related to a healthy PAP, such as relaxation activities for example, have not been included into the procedure but should be considered by each individual according to his/her personal management of daily activities. Other limitations may also affect the PAP for certain individuals such as for example the geographical location, the weather or poor health conditions. The development of PL needs therefore to take into consideration all of these factors; older students and adults must be able to interpret what seems to be the optimal conditions so that the PAP is beneficial for their health.

\section{Conclusion}

The PAP index described in this article is not intended to provide an exact measure of one's volume of physical activity per se. Also, as mentioned before, this PAP monitoring procedure does not concern only adults. Unless individuals have experienced opportunities to develop PL awareness and construct regulation mechanisms under the facilitating guidance of a mentor, they stand little chance, on the long run, to become autonomous in that matter, hence the critical importance of being exposed to self-reflection on their PAP by the end their schooling life. The purpose of the PAP index is to help an individual monitor his/ her PAP over time while taking simultaneously into account its intensity and volume whatever the selected activity(ies). Although not directly used in the computation of the index, frequency and duration specific to each PA session, as well as the diversity of activities performed, may be reflected on as they are recorded. These various characteristics contribute to make that procedure a novel one. Willingness to monitor one's PAP implies at least a minimal level of PL awareness. Besides reflecting on their PA-related knowledge and PA competency and capacities, individuals ought to understand their reasons for engaging into the regular practice of physical activity. Based on their answers to such questions, they can then engage into regulation scenarios with the help of monitoring instruments such as the one discussed in this article.

\section{References}

Acree LS, Longfors J, Fjeldstad AS, Schank B, Nicke KJ, Montgomer PS, et al. (2006) Physical activity is related to quality of life in older adults. Health and Quality Life Outcomes 4(1): 37.

Ainsworth BE, Haskell WL, Herman SD, Meckes N, Basset Jr DR, Tudor-Locke C, et al. (2011) The Compendium of physical activities tracking guide. Arizona: Healthy Lifestyles Research Center, College of Nursing \& Health Innovation, Arizona State University.

Angeli C, Valanides N (2012) How do field-dependent and field-independent learners interact with a computer modeling tool to solve a problem? Implications for the design of joint cognitive systems. In ICICTE 2012 Proceedings, edited by International Conference on Information Communication Technologies in Education, 95-104. 
Barisic A, Leatherdale ST, Kreiger N (2011) Importance of frequency, intensity, time and type (FITT) in physical activity assessment for epidemiological research. Canadian Journal of Public Health 102(4): 174-175.

Barnett LM, Mazzoli E, Hawkins M, Lander N, Lubans DR, Caldwell S, et al. (2020) Development of a self-report scale to assess children's perceived physical literacy. Physical Education and Sport Pedagogy (Advance Online Publication).

Biddle SJH, Gorely T, Pearson N, Bull FC (2011) An assessment of self-reported physical activity instruments in young people for population surveillance: project ALPHA. International Journal of Behavioral Nutrition and Physical Activity 8(1): 1-9.

Bompa TO (1999) Periodization: theory and methodology of training. $4^{\text {th }}$ Edition. Champaign, IL: Human Kinetics.

Bouchard C, Landry F, Brunelle J, Godbout P (1974) La Condition Physique et le Bienêtre (Physical fitness and well-being). Quebec City, Canada: Éditions du Pélican.

Bouchard C, Tremblay A, Leblanc C, Lortie G, Savard R, Thériault G (1983) A method to assess energy expenditure in children and adults. American Journal of Clinical Nutrition 37(3): 461-467.

Brenner JS, the Council on Sports Medicine and Fitness (2007) Overuse injuries, overtraining, and burnout in child and adolescent athletes. Pediatrics 119(6): 12421245.

Cairney JH, Clark J, James ME, Mitchell D, Dudley DA, Kriellaars D (2018) The preschool physical literacy assessment tool: testing a new physical literacy tool for the early years. Frontiers in Pediatrics 6(Jun): 138.

Corbin CB, Le Masurier GC, McConnel KE (2014) Fitness for life. $6^{\text {th }}$ Edition. Champaign, IL: Human Kinetics.

Corbin CB, Welk G, Corbin W, Welk K (2018) Concepts of fitness and wellness: a comprehensive lifestyle approach. $12^{\text {th }}$ Edition. New York (NY): McGraw-Hill Education.

Daley AJ, Duda JL (2006) Self-determination, stage of readiness to change for exercise, and frequency of physical activity in young people. European Journal of Sport Science 6(4): 231-243.

Delisle T, Werch CE, Wong AH, Bian H, Weiler R (2010) Relationship between frequency and intensity of physical activity and health behaviors of adolescents. Journal of School Health 80(3): 134-140.

Dunn EE, Gainforth HL, Robertson-Wilson JE (2018) Behavior change techniques in mobile applications for sedentary behavior. Digital Health 4(Jul): 1-8.

Gagnon J, Nadeau L, Martel D, Normandin J-M, Michaud V (2021) Le Pentathlon en équipe (Team pentathlon). Quebec City, Canada: Department of Physical Education, Laval University.

Girard S, Lemoyne J, Blais D, St-Amand J (2021) An analysis of mechanisms underlying social goals in physical education: A comparison between ordinary and special classes. Physical Education and Sport Pedagogy. (Advance Online Publication).

Godbout P, Gréhaigne J-F (2020) Regulation of tactical learning in team sports - The case of the tactical-decision learning model. Physical Education and Sport Pedagogy. (Advance Online Publication).

Gréhaigne J-F, Godbout P (1995) Tactical knowledge in team sports from a constructivist and cognitivist perspective. Quest 47(4): 490-505.

Gréhaigne J-F, Godbout P, Bouthier D (1999) The foundations of tactics and strategy in team sports. Journal of Teaching in Physical Education 18(2): 159-174.

Hickerson BD (2011) Measuring physical activity in youth settings: considerations for instrument selection. Journal of Youth Development - Bridging Research and Practice 6(4): 1-10. 
Hills AP, Mokhtar N, Byrne NM (2014) Assessment of physical activity and energy expenditure: an overview of objective measures. Frontiers in Nutrition 1(5): 1-16.

Holmes RM, Liden S, Shin L (2013) Children's thinking styles, play, and academic performance. American Journal of Play 5(2): 219-238.

Klesius SE (1971) Physical Education in the seventies: where do you stand? Journal of Health, Physical Education, Recreation 42(2): 46-49.

Liu W, Chepyator-Thomson JR (2009) Field dependence-independence and physical activity engagement among middle school students. Physical Education and Sport Pedagogy 14(2): 125-136.

Longmuir PE, Gunnell KE, Barnes JD, Belanger K, Leduc G, Woodruff SJ, et al. (2018) Canadian assessment of physical literacy second edition: a streamlined assessment of the capacity for physical activity among children 8 to 12 years of age. BMC Public Health 18(Suppl. 2): 1047.

Lustyk KB, Windam L, Paschane AE, Olson KC (2004) Physical activity and quality of life: Assessing the influence of activity frequency, intensity, volume, and motives. Behavioral Medicine 30(3): 124-131.

Mäkelä S, Aaltone S, Korhonen T, Rose RJ, Kaprio J (2017) Diversity of leisure-time sport activities in adolescence as a predictor of leisure-time physical activity in adulthood. Scandinavian Journal of Medicine \& Science in Sports 27(12): 19021912.

Martel D, Gagnon J, Nadeau L, Michaud V, Godbout P (2011) Team pentathlon Promoting physical activity among older children and adolescents. Revue phénEPS/ PHENex Journal 3(2): 1-20.

McLain JJ, Tudor-Locke C (2009) Objective monitoring of physical activity in children: Considerations for instrument selection. Journal of Science and Medicine in Sport 12(5): 526-533.

Musich S, Wang SS, Hawkins K, Greame C (2017) The frequency and health benefits of physical activity for older adults. Population Health Management 20(3): 199-207.

Payne S, Townsend N, Foster C (2013) The physical activity profile of active children in England. International Journal of Behavioral Nutrition and Physical Activity 10(Dec): 136.

Perkins D (1992) Smart schools: better thinking and learning for every child. New York (NY): Free Press.

Pradal-Cano L, Lozano-Ruiz G, Pereyra-Rodriguez JJ, Saigi-Rubio F, Bach-Faig A, Esquius L, et al. (2020) Using mobile applications to increase physical activity: a systematic review. International Journal of Environmental Research and Public Health 17(21): 8238.

Robinson DB, Randall L (2017) Marking physical literacy or missing the mark on physical literacy? A conceptual critique of Canada's physical literacy assessment instruments. Measurement in Physical Education and Exercise Science 21(1): 40-55.

Rodgers WM, Sullivan MJL (2001) Task, coping, and scheduling self-efficacy in relation to frequency of physical activity. Journal of Applied Social Psychology 31(4): 741753.

Romeo A, Edney S, Plotnikoff R, Curtis R, Ryan J, Sanders I, et al. (2019) Can smartphone apps increase physical activity? Systematic review and meta-analysis. Journal of Medical Internet Research 21(3): e12053.

Ryan RM, Deci EL (2017) Self-determination theory: basic psychological needs in motivation, development, and wellness. New York (NY): Guilford Publishing.

Ryan RM, Deci EL (2020) Intrinsic and extrinsic motivation from a self-determination theory perspective: definitions, theory, practices, and future directions. Contemporary Educational Psychology 61(Apr): 101860. 
Sallis JF, Saelens BE (2000) Assessment of physical activity by self-report: status, limitations, and future directions. Research Quarterly for Exercise and Sport 71(Suppl. 2): 1-14.

Sylvia LG, Bernstein EE, Hubbard JL, Keating L, Anderson EJ (2014) A practical guide to measuring physical activity. Journal of the Academy of Nutrition and Dietetics 14(2): 199-208.

Tidén A, Brun Sundblad G, Lundvall S (2021) Assessed movement competence through the lens of Bourdieu - A longitudinal study of a developed taste for sport, PE and physical activity. Physical Education and Sport Pedagogy. (Advance Online Publication).

U.S. Department of Health and Human Services (2018) Physical activity guidelines for Americans. $2^{\text {nd }}$ Edition. Washington (DC): U.S. Department of Health and Human Services.

Westerterp KR (2009) Assessment of physical activity: a critical appraisal. European Journal of Applied Physiology 105(6): 823-828.

Whitehead M (1993) Physical literacy. In IAPESWG Congres. Melbourne, Australia.

Whitehead M (2001) The concept of physical literacy. European Journal of Physical Education 6(2): 127-138.

Whitehead M (2013a) Definition of Physical Literacy and clarification of related issues. Journal of Sport Science and Physical Education 65: 29-34.

Whitehead M (2013b) Stages in physical literacy journey. Journal of Sport Science and Physical Education 65: 52-56.

Whitehead M (2013c) What is the education in physical education? In S Capel, M Whitehead (eds.), Debates in Physical Education, 22-36. New York (NY): Routledge.

Woodbridge B (1995) Increasing the effectiveness of university/college instruction: integrating the results of learning style research into course design and delivery. In RR Sims, SJ Sims (eds.), The Importance of Learning Styles: Understanding the Implications for Learning, Course Design, and Education, 49-67. Westport (CN): Greenwood Press.

Woodbridge B, Haimes-Bartlof M (2006) The field dependence/field independence learning styles: implications for adult student diversity, outcomes assessment and accountability. In RR Sims, SJ Sims (eds.), Learning Styles and Learning: A Key to Meeting the Accountability Demands in Education, 237-257. Hauppauge (NY): Nova Science Publishers.

Zhu Z, Feng T, Huang Y, Liu X, Lei H, Li G, et al. (2019) Excessive physical activity duration may be a risk factor for hypertension in young and middle-aged populations. Medicine 98(18): e15378. 
